\title{
ATENÇÃo OdONTOLÓGICA AO PACIENTE COM HIV: RELATO DE CASO
}

\author{
DENTAL CARE TO PATIENTS WITH HIV: CASE REPORT
}

\author{
Hevelin Cristina Ferraz Borges ${ }^{1}$, Kharla Renata Rodrigues dos Santos², Ellen Cristina Gaetti Jardim³, \\ Maria de Fátima Meinberg Cheade ${ }^{4}$, Eduardo Ferreira da Motta ${ }^{5}$ \\ 1 Residente em Odontologia - Atenção ao Paciente Crítico pelo Núcleo do Hospital Universitário da Universidade Federal de Mato Grosso do \\ Sul (NHU/UFMS). \\ 2 Residente em Odontologia - Atenção ao Paciente Crítico pelo Núcleo do Hospital Universitário da Universidade Federal de Mato Grosso do \\ Sul (NHU/UFMS). \\ ${ }^{3}$ Residente em Cirurgia e Traumatologia Bucomaxilofacial pelo Núcleo do Hospital Universitário da Universidade Federal de Mato Grosso do \\ Sul (NHU/UFMS). \\ ${ }^{4}$ Coordenadora da Residência Multiprofissional - Atenção ao Paciente Crítico pelo Núcleo do Hospital Universitário da Universidade Federal \\ de Mato Grosso do Sul (NHU/UFMS). \\ 5 Preceptor da Residência em Odontologia - Atenção ao Paciente Crítico pelo Núcleo de Hospital Universitário da Universidade Federal de \\ Mato Grosso do Sul (NHU/UFMS).
}

Data de entrada do artigo: $14 / 06 / 2012$

Data de aceite do artigo: 01/10/2012

\section{RESUMO}

Introdução: o surgimento da AIDS (Acquired Immunodeficiency Syndrome - Síndrome da Imunodeficiência Adquirida), na década de 1980, fomentou mudanças significativas em vários campos, não somente no da saúde, principalmente por envolver comportamento sexual e doença. Observa-se maior incidência entre as camadas mais pobres da população, predominantemente, usuários da rede pública de assistência à saúde, e que tendem a apresentar uma condição oral precária. Objetivo: o objetivo deste trabalho é apresentar um caso clínico com foco na abordagem odontológica ao paciente portador da AIDS. Caso clínico - paciente buscou atendimento referindo dor torácica em hemitórax esquerdo, hiporexia, diarreia e dispneia. Ao exame extraoral, evidenciou-se simetria facial e as cadeias ganglionares cervicais, submandibulares e mentonianas impalpáveis. Presença de ulcerações no vermelhão dos lábios e mucosa. Ao exame intraoral: dentes hígidos, pigmentação melânica em mucosas e reserva salivar preservada. Língua aparentemente normal e higienizada e ausência de comprometimento periodontal. Realizou- se higiene oral 2 vezes ao dia, com clorexidina a 0,12\%, e inspeção diária da cavidade oral. Também foi feito uso de triancinolona de acetonida em associação com garamicina, nistatina e neomicina, 3 vezes ao dia, por 14 dias, com o intuito de evitar infecções secundárias e lubrificar a região, possibilitando a recuperação. Conclusões: sendo assim, é lícito crer que, com a grande prevalência de doenças bucais, como cárie e doença periodontal, além dos inúmeros problemas bucais associados à infecção pelo Vírus da Imunodeficiência Humana (HIV) esses pacientes requerem pronto tratamento e contínuo monitoramento; o paciente portador dessa condição sistêmica necessita de atenção odontológica, assim como em todos os âmbitos da saúde

Palavras-chaves: Assistência odontológica; Aids; Ética; Qualidade de vida. 


\section{ABSTRACT}

Introduction: the rise of AIDS (Acquired Immunodeficiency Syndrome), in the 1980s, fostered significant changes in several areas, not only in health, mainly because it envolves sexual behavior and disease. It was observed a higher incidence between the layers poorest of the population, predominantly users of public health care and tending to have poor oral condition. Objective: the objective of this paper is presenting a case report focusing on dental care patient with AIDS. Case report: patient sought assistance claiming chest pain in the left hemithorax, appetite loss, diarrhea and dyspnea. Extraoral examination showed a symmetric face and cervical, submandibular and mentonian ganglions chain nonpalpable. Presence of ulceration on the lips and mucosa. Intraoral exam: healthy teeth, melanin pigmentation on the mucosa and presence of normal quantity of saliva. Tongue apparently normal and clean. No periodontal disease was seen. Oral hygiene was held twice a day with $0.12 \%$ chlorhexidine, and daily inspection of the oral cavity, triamcinolone acetonide in combination with gentamicin sulfate, nystatin and neomycin, 3 times a day, for 14 days, with the intention of avoiding secondary infections and lubricate the region, enabling the recovery. Conclusions: Thus, it is lawful to believe that with a high prevalence of oral diseases as caries and periodontal disease, in addition to numerous oral problems associated with HIV infection, these patients require prompt treatment and continuous monitoring; the patient with this systemic condition requires dental care as well as in all areas of health.

Key-words: Dental care; Aids; Ethics; Quality of life.

\section{INTRODUÇÃO}

A Síndrome da Imunodeficiência Adquirida, identificada pela primeira vez em 1983, caracterizase por severa imunossupressão do hospedeiro, causada pelo Vírus da Imunodeficiência Humana (HIV), manifestando-se por uma grande variedade de sintomas e sinais clínicos, muitos deles tendo a boca como sítio dessas manifestações ${ }^{(1)}$. Com o advento da AIDS, no início dos anos 1980, surgiram mudanças importantes no comportamento humano, assim como, no âmbito da saúde, no manejo dos pacientes.

A expectativa de vida de indivíduos infectados pelo vírus HIV positivo torna-se cada vez mais uma condição controlável e que impõe nova maneira de assistir a esses pacientes, e no âmbito da odontologia provocou a necessidade de enfatizar ações de cuidados preventivos e restauradores, contrapondo a atenção anterior pautada apenas no alivio da dor $\operatorname{aguda}^{(1)}$.

Nesse sentido, para que a atenção à saúde ao infectado por HIV tenha chances de sucesso, o cirurgião-dentista deve se integrar em uma equipe multiprofissional, conhecer e considerar alguns fatores, como a contagem de linfócitos CD4+, grau de imunossupressão, medicamentos utilizados e a carga viral, a qual pode estar relacionada com a suscetibilidade a infecções oportunistas e o ritmo de progressão para a $\operatorname{AIDS}(2,3)$.

Sendo assim, as infecções orais e odontogênicas devem ser eliminadas, e deve ocorrer um acompanhamento rigoroso da condição periodontal desses pacientes, tendo como foco principal a prevenção de dor e infecções. Antes de cirurgias é necessário saber a contagem de neutrófilos e plaquetas, podendo haver a necessidade de realizar transfusão plaquetária. No caso de neutropenia, é necessária a administração de profilaxia antibiótica(4).

Linfadenopatia generalizada persistente, eritema gengival linear, gengivite ulcerativa necrosante (GUN), periodontite ulcerativa necrosante (PUN), herpes, leucoplasia pilosa, sarcoma de Kaposi e a candidose são as manifestações mais comumente encontradas na cavidade oral e maxilofacial de pacientes imunocomprometidos. Estudos mostram que aproximadamente um terço dos pacientes infectados com HIV e $90 \%$ dos pacientes com AIDS desenvolvem a candidose oral, podendo apresentar quatro padrões clínicos: pseudomembranosa, eritematoso, hiperplásico, queilite angular ${ }^{(5)}$.

Condição comum nestes pacientes, a queilite angular tende a manifestar-se como doença oportunista em paciente com imunossupressão(6). A lesão se apresenta em região de ângulo da boca, evidenciando eritema, fissuração e descamação. Com a retenção da saliva nesta área, ou em região de vermelhão labial, favorece a infecção por leveduras, dos quais $20 \%$ são causados apenas por Candida albicans e 60\% são ocasionadas pela infecção combinada destas com o Staphylococcus aureus(5).

O conhecimento sobre a epidemia e a organização dos serviços de atenção especializada é indispensável para a realização de atividades de planejamento de ações que possam oferecer uma melhor assistência a esses pacientes. Desse modo, o objetivo deste trabalho é apresentar um caso clínico de um paciente portador 
do vírus HIV, levando em consideração os aspectos clínicos e o tratamento odontológico.

\section{RELATO DE CASO}

Paciente do gênero masculino, melanoderma, 25 anos, natural de Campo Grande - MS, compareceu ao Pronto Atendimento Médico (PAM) do Núcleo de Hospital Universitário da Universidade Federal de Mato Grosso do Sul (NHU-UFMS), com quadro de dor torácica em hemitórax esquerdo há três dias, hiporexia persistente há três dias, e diarreia há um dia, sem sangue ou muco, quadro de dispneia aos grandes esforços há um mês, com piora progressiva, evoluindo para dispneia aos pequenos esforços.

Relatou ainda que há três anos apresentou febre recorrente, com intervalos regulares, tosse produtiva e emagrecimento de aproximadamente $5 \mathrm{~kg}$, nesse intervalo de tempo. Sob essa clínica e, somando-se aos exames laboratoriais do paciente, ele foi internado com os seguintes diagnósticos: Pneumonia Aguda Comunitária (PAC) grave, Insuficiência renal aguda (IRA) dialítica, Síndrome da Imunodeficiência Adquirida (SIDA), Infecção do Trato Urinário (ITU), fúngica e pneumocistose.

Após 3 dias, devido ao agravo de seu quadro respiratório, o paciente foi sedado e submetido à intubação orotraqueal, porém permaneceu nessa condição por apenas 4 dias, quando apresentou condições para que fosse desligado o esquema de sedação e realizada a extubação. Foi então iniciada a hemodiálise e a administração dos antibióticos meropenem e linezolida, e foi inicializada a terapia antirretroviral potente (HAART).

Ao exame extraoral, não foi evidenciada assimetria facial e as cadeias ganglionares cervicais, submandibulares e mentonianas não se apresentaram palpáveis. Em região de vermelhão de lábios e mucosa labial foram observadas ulcerações compatíveis com queilite esfoliativa. Ao exame intraoral, constatou-se a presença de dentes hígidos, mucosa com pigmentação melânica e hidratada e reserva salivar. A língua apresentava papilas preservadas e higienizadas e havia ausência de problemas periodontais (Figura 1).

Durante o período de intubação foi realizada higiene oral 2 vezes ao dia, com clorexidina a $0,12 \%$, e inspeção da cavidade oral diariamente em busca de anormalidades. Para a queilose, prescreveuse acetonida de triamcinolona em associação com garamicina, nistatina e neomicina, 3 vezes ao dia, por 14 dias, com o objetivo de evitar infecções secundárias, combater o fungo e lubrificar a região, possibilitando a recuperação (Figura 2).

\section{DISCUSSÃO}

As doenças infecciosas na cavidade oral têm sido frequentemente associadas a alterações na resposta imunológica, falta de higiene oral, desnutrição severa, tabagismo, alcoolismo e diabetes, os quais podem predispor o indivíduo ao desenvolvimento de gengivite e periodontite ${ }^{(7,8)}$.

Além desse aspecto, a relevância da resposta imune local e sistêmica na proteção dos tecidos periodontais está documentada, sendo que seu comprometimento leva à deterioração das condições dos tecidos de suporte $^{(9)}$, bem como facilita a colonização da cavidade oral por microrganismos superinfectantes, como as bactérias entéricas e pseudomonas(10-12).

Neste sentido, a AIDS tem merecido maior atenção por parte dos pesquisadores e dos órgãos de saúde, de modo geral, em virtude de sua gravidade, relacionada não só ao índice de morbidade que ela provoca, mas, também, pelos diversos aspectos sociais, econômicos e de saúde pública envolvidos.

De um estigma de doença fatal, que provocava a marginalização das pessoas acometidas por ela, segregando-as da sociedade, resultado de um medo equivocado e muito difundido entre a população em geral, e até mesmo por parte dos profissionais da saúde, que tendem a se mostrar tensos devidos a dois fatores: de um lado as preocupações legítimas desses profissionais quanto ao risco ocupacional do HIV e, por outro, a persistência de preconceitos que contribuíram para aumentar a resistência dos serviços de saúde ao atendimento a pacientes com HIVIAIDS(5,6).

Graves doenças periodontais têm sido associadas a alterações no sistema imune do hospedeiro $(7,8)$, que podem predispor ao desenvolvimento de gengivite $\mathrm{e}$ periodontite. Além disso, a relevância do sistema imune na proteção dos tecidos periodontais é documentado e o comprometimento deste poderia agravar a condição periodontal9. Associações entre o estado periodontal e a presença de infecções oportunistas não foram estabelecidas. Tanto a gengivite quanto a periodontite são frequentemente encontradas em pacientes HIVpositivos sintomáticos, nos quais podem adquirir características necrosantes ou agressivas. Isso pode ser reflexo do papel que desempenham as células CD4 + na progressão da infecção pelo HIV, que são escassos no sangue periférico, desses pacientes ${ }^{(14)}$.

A higiene oral em ambiente hospitalar, sobretudo em pacientes imunocomprometidos, é de suma importância, para prevenir a instalação de patologias bucais, especialmente as infecciosas, e possíveis complicações de doenças prévias, manter a mucosa 
oral úmida e oferecer conforto ao paciente(15,16). No entanto, a avaliação da orofaringe e a manutenção de uma higiene adequada é procedimento difícil de ser realizado em pacientes sob cuidados intensivos, principalmente naqueles que fazem uso de ventilação mecânica, devido à dificuldade de acesso à cavidade oral16, porém isso é essencial para a melhora do quadro clinico apresentado pelo paciente.

Em pacientes hospitalizados, patógenos comumente responsáveis pela pneumonia nosocomial são encontrados colonizando o biofilme bucal(16), e técnicas que, embora pareçam simples, como técnicas de higiene oral, são por vezes negligenciadas pela equipe de enfermagem, por não ser considerada um procedimento de alta prioridade para os pacientes críticos.

No caso apresentado, a presença de uma higiene bucal precária vai de encontro às condições sistêmicas do paciente. O cuidado com a saúde integral do paciente crítico se faz necessário para evitar que infecções em outros órgãos e sistemas, que não são ligados ao problema inicial possam vir a prejudicar seu quadro clínico $(17,18)$.

Com o passar do tempo, torna-se indissolúvel a saúde bucal, como estado de harmonia, normalidade ou higidez da boca, sempre associada à saúde geral do indivíduo. A ciência odontológica não poderia, de modo algum, omitir-se de sua responsabilidade, face às práticas de outras profissões. A prática das profissões de saúde foi orientada, desde o início, no sentido do diagnóstico e tratamento das enfermidades, visando à intervenção curativa. Em virtude das doenças bucais, como cárie e doença periodontal, além dos inúmeros problemas bucais associados à infecção pelo HIV requererem pronto tratamento e contínuo monitoramento, o paciente portador dessa condição sistêmica necessita de atenção odontológica, assim como em todos os âmbitos da saúde.

\section{CONCLUSÃo}

O cirurgião-dentista, sobretudo como profissional da área da saúde, precisa repensar o modo como vê pacientes sistemicamente comprometidos, como os portadores de HIV, e prestar atenção especializada a eles, como no caso apresentado neste artigo, evidenciando a necessidade de haver um odontólogo na equipe multidisciplinar, focalizando não somente práticas curativas, como também inspeções constantes em busca de anormalidades na cavidade bucal, obtendo um diagnóstico precoce e orientações quanto a higiene oral, com o objetivo de previnir infecções que tendem a diminuir a qualidade de vida do indivíduo.

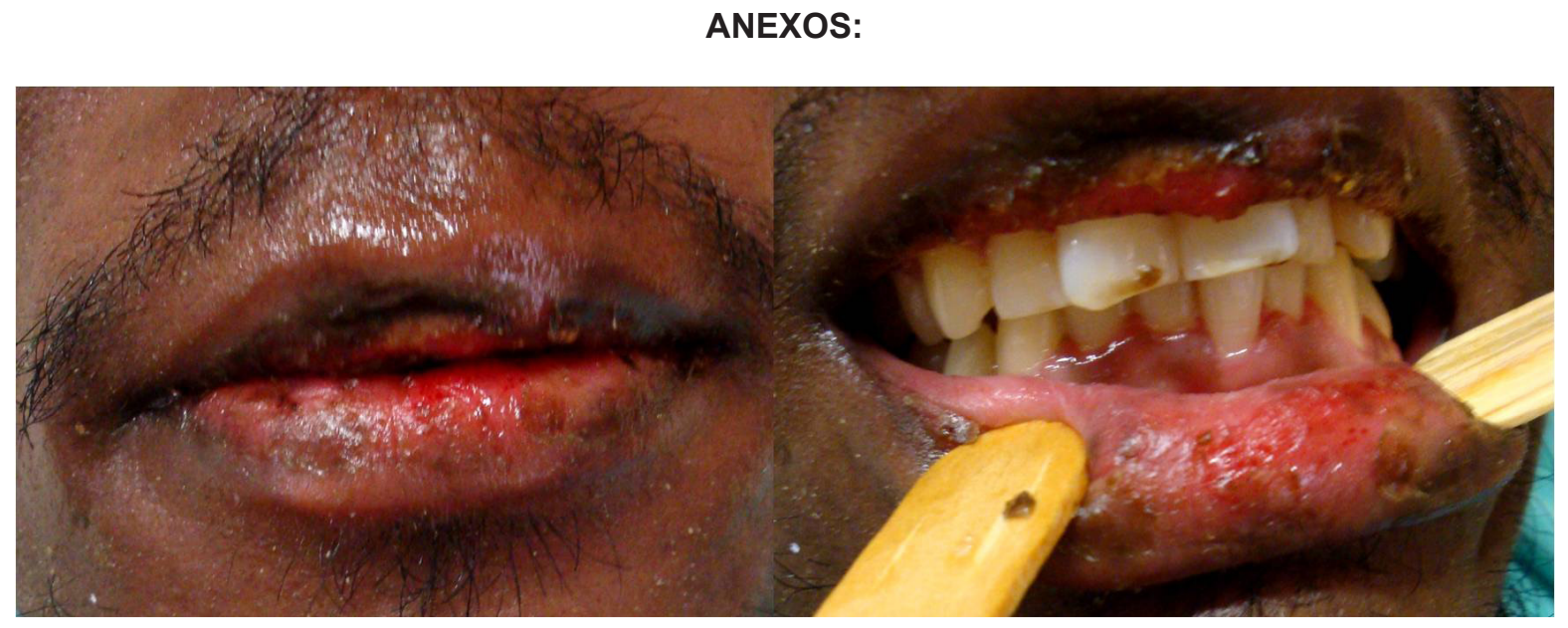

Figura 1- Aspecto antes da intervenção odontológica. 


\section{RBCS}

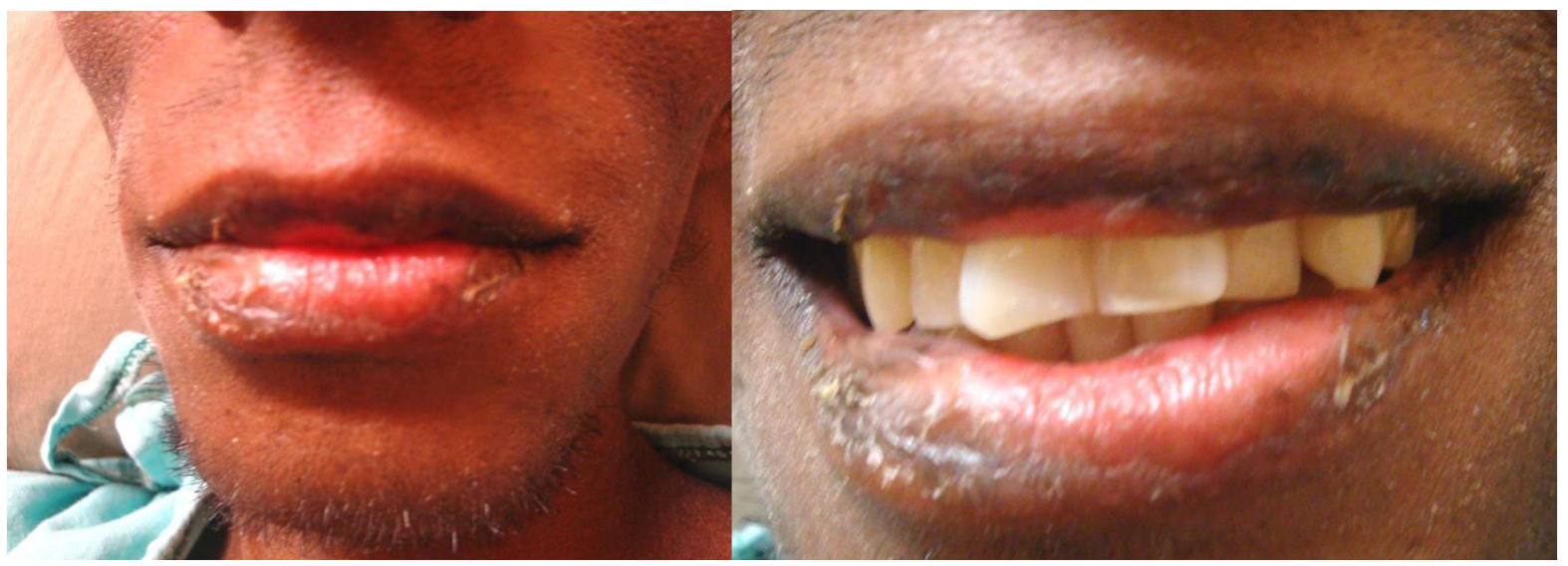

Figura 2- Aspecto após 14 dias de intervenção odontológica. 


\section{REFERÉNCIAS}

1. Baron M, Gritsch F, Hansy AM, Haas R. Implants in an HIV-positive patient: a case report. Int J Oral Maxillofac Implants. 2004;19:425-30.

2. Scully C.AIDS and dentistry: a report of a stateof-the-art meeting. Br Dent J. 1988;164(4):118.

3. Scully C, Porter SR. Oral mucosal disease: a decade of new entities, aetiologies and associations. Int Dent J 1994; 44:33-43.)

4. Little JW, Falace DA, Miller CS, Rhodus NL. Manejo odontológico do paciente clinicamente comprometido. Rio de Janeiro: Elsevier; 2008.

5. Neville BW, Damm DD, Allen CM, Bouquot JE. Patologia Oral \& Maxilofacial. Rio de Janeiro: Guanabara Koogan; 2008.

6. Pennini SN, Rebello PFB, Silva MR. Queilites. J Bras Med. 2000; 78(6):104-110.

7. Walsh MC, Kim N, Kadono Y, Rho J, Lee SY, Lorenzo J, et al. Osteoimmunology: interplay between the immune system and bone metabolism. Annu Rev Immunol. 2006; 23(1):33-63.

8. Aas JA, Barbuto SM, Alpagot T, Olsen I, Dewhirst FE, Paster BJ. Subgingival plaque microbiota in HIV positive patients. J Clin Periodontol. 2007; 34(3):189-195.

9. Cobb CM, Ferguson BL, Keselyak MT, Holt LA, MacNeill SR, Rapley JW. A TEM/SEM study of the microbial plaque overlying the necrotic gingival papillae of HIV-seropositive necrotizing ulcerative periodontitis. J Periodont Res 2003; 38(2), 147-55.

10. Gaetti-Jardim EC. Fatores associados à presença de microrganismos superinfectantes ou oportunistas na cavidade bucal: relações com próteses totais, condições periodontais e susceptibilidade a antimicrobianos [Dissertação]. Araçatuba: Faculdade de Odontologia de Araçatuba
- UNESP; 2009.

11. Barbosa FCB, Mayer MPA, Saba-Chujfi E, Cai S. Subgingival occurrence and antimicrobial susceptibility of enteric rods and pseudomonads from Brazilian periodontitis patients. Oral Microbiol Immunol. 2001;16:306-310.

12. Paju S, Scannapieco FA. Oral biofilms, periodontitis, and pulmonary infections. Oral Diseases. 2007;13:508-512.

13. Acurcio FA. Trabalhar em saúde nos tempos de AIDS: o risco e o medo. Rev Bras Clín Ter. 1997;23:111-7.

14. Jardim Júnior EG, Nakano V, Wahasugui TC, Cabral FC, Gamba R, Avila-Campos MJ. Occurrence Of Yeasts, Enterococci And Other Enteric Bacteria In Subgingival Biofilm Of Hiv-Positive Patients With Chronic Gingivitis And Necrotizing Periodontitis. Braz J Microbiol. 2008;39:257-261.

15. Abidia RF. Oral care in the intensive care unit: a review. J Contemp Dent Pract. 2007;8(1):76-82.

16. Oliveira LCBS, Carneiro PPM, Fischer RG, Tinoco EMB. A presença de patógenos respiratórios no biofilme bucal de pacientes com pneumonia nosocomial. RBTI. 2007;19(4):428-433.

17. Araújo RJG, Oliveira LCG, Hanna LMO, Corrêa AM, Carvalho LHV, Alvares NCF. Análise de percepções e ações de cuidados bucais realizados por equipes de enfermagem em unidades de tratamento intensivo. Rev Bras Ter Intensiva. 2009;21(1):38-44.

18. Morais TMN, Silva A, Avi ALRO, Souza PHR, Knobel E, Camargo LFA. A importância da atuação odontológica em pacientes internados em unidade de terapia intensiva: [revisão]. Rev Bras Ter Intensiva. 2006;18(4):412-7.

\section{Endereços para correspondência:}

\section{Hevelin Cristina Ferraz Borges}

hevelinborges@hotmail.com

Kharla Renata Rodrigues dos Santos

kharlacg@hotmail.com

Ellen Cristina Gaetti Jardim

ellengaetti@hotmail.com
Maria de Fátima Meinberg Cheade

mdfcheade@uol.com.br

Eduardo Ferreira da Motta

eduardomotta@hotmail.com 